\title{
SAFARI DAKWAH BERBASIS ISLAM MAHASISWI KKN STIBA MAKASSAR DI DUSUN DASAN BAGIK, LOMBOK TIMUR
}

\section{ISLAMIC BASED SAFARI DAKWAH STUDENTS OF KKN STIBA MAKASSAR IN DASAN BAGIK VILLAGE, EAST LOMBOK}

\author{
Sri Ujiana Putri \\ Sekolah Tinggi Ilmu Islam dan Bahasa Arab (STIBA) Makassar \\ sriujianaputri@stiba.ac.id

\section{Dewi Indriani} \\ Sekolah Tinggi Ilmu Islam dan Bahasa Arab (STIBA) Makassar \\ dewiindriani@stiba.ac.id
}

\section{Armida}

Sekolah Tinggi Ilmu Islam dan Bahasa Arab (STIBA) Makassar armida@stiba.ac.id

\begin{tabular}{ll}
\hline Keywords : & \multicolumn{1}{c}{ ABSTRACT } \\
Dasan Bagik, Teaching, & Dasan Bagik Village is a Muslim majority area that maintains \\
Islam in the midst of existing religious diversity. This Islamic value \\
is also passed down to the next generation. The purpose of \\
implementing Real Work Lecture (KKN) is as a form of community \\
service which is a pillar of the Tri Dharma of Higher Education. \\
The method of implementing community service in Dasan Bagik \\
Village begins with mapping the problems and needs of the \\
community throught SOAR analysis. After the mapping is done, a \\
work program is prepared in accordance with the needs of the local \\
community. So the work programs that have been initiated are the \\
teaching at Madrasah Tsanawiyah, teaching adult Al Quran \\
(tahsin), daurah pra ta'rif and Sholeh Children Festival (FAS). The \\
result of the implementation of this work program show that the \\
general public is very enthusiastic. This is evident from the change \\
in society after following some of the work programs above. Like \\
muslim womenwho have begun to be able to read the Koran \\
according the correct tajwid principles, the practice of discussing \\
Arabic is active among students of Tsanawiyah madrasah, and \\
children who are confident in displaying their abilities in public. \\
\hline
\end{tabular}


Website: https://journal.stiba.ac.id ISSN: 2723-6013 (Online)

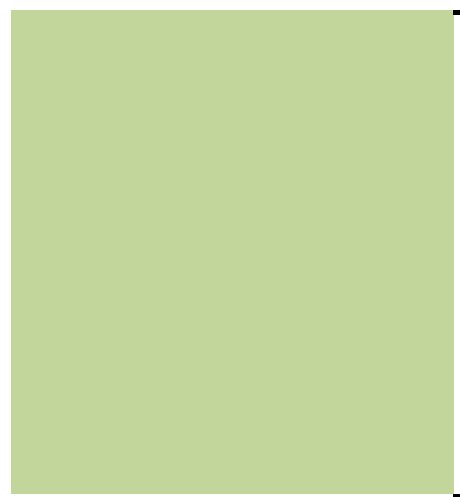

program kerja yang sesuai dengan kebutuhan masyarakat setempat. Untuk itu, maka program kerja yang telah dicanangkan ialah pengajaran Taman Kanak-kanak, pengajaran di Madrasah Tsanawiyah, pengajaran Al-Qur'an orang dewasa (tahsin), daurah pra ta'rif dan Festival Anak Saleh (FAS). Hasil dari pelaksanaan program kerja ini terlihat antusias masyarakat secara umum sangat besar. Terbukti dari perubahan masyarakat setelah mengikuti beberapa program kerja di atas. Seperti ibu-ibu muslimah yang sudah mulai bisa membaca Al-Qur'an sesuai dengan kaidah tajwid yang benar, pembiasaan berbahasa Arab aktif di kalangan siswa siswi madrasah tsanawiyah, dan anak-anak yang sudah percaya diri menampilkan kemampuan diri di hadapan umum.

Diterima: 27 April 2021; Direvisi: 4 Mei 2021; Disetujui: 18 Mei 2021; Tersedia online: 18 Juni 2021

How to cite: Putri, Sri Ujiana., Dewi Indriani, Armida, "Safari Dakwah Berbasis Islam Mahasiswi KKN STIBA Makassar Di Dusun Dasan Bagik, Lombok Timur”, WAHATUL MUJTAMA': Jurnal Pengabdian Masyarakat Vol.2., No.1 (Juni, 18, 2021): 11-20. Doi: https://doi.org/10.36701/wahatul.v2i1.338

\section{PENDAHULUAN}

Dusun Dasan Bagik merupakan salah satu Dusun yang berada di Kecamatan Aikmel, Kabupaten Lombok Timur. Kondisi alam Dusun Dasan Bagik adalah lahan pertanian dengan sebagian besar irigasi teknik. Iklim Dusun Dasan Bagik adalah iklim tropis, sebagaimana Dusun-Dusun lain di wilayah Indonesia mempunyai iklim kemarau dan penghujan. Hal tersebut mempunyai pengaruh langsung terhadap pola tanam yang ada di Dusun Dasan bagik Kacamatan Aikmel. Dusun Dasan Bagik terdiri dari 5 dusun dengan luas Dusun $5,36 \mathrm{~km}^{2}$. Batas Dusun Dasan Bagik yaitu, sebelah Barat berbatasan dengan Dusun Aikmel, sebelah Utara berbatasan dengan Dusun Aikmel Utara dan Dusun Toya, sebelah selatan berbatasan dengan Dusun Bagik Nyaka Santri dan sebelah Timur berbatasan dengan Dusun Kembang Kerang Daya, Kembang Kerang dan Kroya. Jumlah penduduk Dusun Dasan Bagik berdasarkan data adalah 68.870 jiwa. Berdasarkan total jumlah penduduk, jenis kelamin laki-laki sebanyak 2.493 jiwa dan jenis kelamin perempuan sebanyak 2.503 jiwa dengan jumlah 4.996 kepala keluarga.

Pendidikan merupakan suatu hal yang memiliki peranan penting dalam kehidupan. Salah satu peran pendidikan adalah sebagai proses pembentukan pola pikir dalam pengembangan kualitas hidup masyarakat. Kualitas pendidikan harus ditunjang dengan ketersediaan sarana dan prasarana pendidikan yang bermutu. Sarana Pendidikan di Dusun Dasan Bagik terdapat Perpusdes berjumlah 1 unit, PAUD berjumlah 4 unit, TK berjumlah 3 unit, SD berjumlah 2 unit, dan Sekolah Dasar Luar Biasa (SLBA) berjumlah 0 unit. 
Sarana peribadatan merupakan sarana kehidupan untuk mengisi kebutuhan rohani yang perlu disediakan di lingkungan perDusunaan yang direncanakan selain sesuai peraturan yang ditetapkan, juga sesuai dengan keputusan masyarakat yang bersangkutan. Dalam hal keagamaan penduduk Dusun Dasan Bagik rata-rata menganut agama Islam meskipun ada tiga orang yang menganut agama non Islam. Sarana keagamaan di Dusun Dasan Bagik hanya terdiri dari sarana peribadatan berupa masjid yang berjumlah 4 buah serta musala yang berjumlah 7 buah dan tidak terdapat rumah peribadatan yang lain.

Keadaan penduduk berdasarkan mata pencaharian dapat digambarkan sebagai kehidupan sosial ekonomi dari sumber masyarakat tersebut, untuk pekerjaan masyarakat Dusun Dasan Bagik rata-rata adalah petani yang berjumlah 987 orang, buruh tani berjumlah 88 orang, tukang batu 76 orang, karyawan perusahaan swasta berjumlah 675 laki-laki dan 465 perempuan, sopir berjumlah 114 orang dan karyawan honorer berjumlah 52 laki-laki dan 41 perempuan. Adapun fasilitas umum yang terdapat di Dusun Dasan Bagik adalah tempat olahraga berjumlah 1 unit, balai pertemuan berjumlah 1 unit, dan BUMDES berjumlah 1 unit $^{1}$.

Berdasarkan profil singkat Dusun Dasan Bagik di atas, maka tujuan yang ditetapkan dalam pelaksanaan pengabdian kepada masyarakat (PkM) yang dilakukan oleh pihak Sekolah Tinggi Ilmu Islam dan Bahasa Arab (STIBA) Makassar, bekerjasama dengan Pemerintah Dusun Dasan Bagik adalah sebagai berikut;

1. Menumbuhkan kesadaran social mahasiswa dalam berdakwah berbasis ilmu pengetahuan Islam yang telah diperoleh selama belajar di kampus STIBA Makassar.

2. Mengembangkan kompetensi dakwah lapangan mahasiswa STIBA Makassar.

3. Mengamalkan Tri Dharma Perguruan Tinggi bagi Dosen Pembimbing Lapangan pada pilar pengabdian kepada masyarakat.

4. Mengembangkan eksistensi STIBA Makassar sebagai perguruan tinggi berbasis pengkaderan ulama dan organisatoris yang bermanfaat kepada masyarakat.

Sebelum pelaksanaan KKN, terlebih dahulu dilakukan survei lapangan dengan menggunakan metode sederhana dengan analisis SOAR. Tujuannya agar mampu mengidentifikasi problem masyarakat, memetakan masalah, kebutuhan masyarakat dengan dakwah, dan menyususn program KKN yang meliputi bidang pendidikan dan sosial. Secara sederhana, dapat diuraikan sebagai berikut:

1. Strength, penduduk Dusun Dasan Bagik mayoritas menganut agama Islam. Mahasiswi KKN telah dibekali beberapa pelatihan yang mendukung beberapa

\footnotetext{
${ }^{1}$ Profil Dusun Dasan Bagik.
} 
program kerja di lapangan, seperti pelatihan public speaking, pengajaran AlQur'an dewasa dan anak-anak, pelatihan kepanitiaan dan lain-lain.

2. Opportunities, dukungan aparat pemerintah dan antusias masyarakat terhadap program kerja KKN mahasiswi.

3. Aspiration, Dusun Dasan Bagik menjadi Dusunn binaan, masyarakat lebih paham dan mampu merealiasasikan dasar-dasar keislaman dengan baik, masyaakat lebih dekat dengan al quran, baik dalam bacaan, hafalan maupun pengamalan.

4. Result, terwujudnya Dusun Dasan Bagik yang sebagai Dusun yang Islami dan dekat dengan Al-Qur'an.

Dari analisis di atas, maka dipetakan beberapa program kerja di antaranya; pengajaran Al-Qur'an dewasa dan anak-anak, Daurah Pra Ta'rif, dan Festival Anak Saleh.

Sejumlah PkM terdahulu dan relevan dengan PkM ini berupa pelaksanaan KKN di masyarakat ialah sebagai berikut:

1. PkM yang dilakukan oleh Saharuddin di Dusun Wonorejo Kecamatan Mangkutana, Luwu Timur ditemukan bahwa dengan hadirnya peserta KKN terjalin kerjasama antara masyarakat dan pemerintah dalam mewujudkan pembangunan daerah. Selain itu, dengan adanya pemetaan program kerja seperti pelatihan penerapan pengajaran atau pembimbingan kurikulum TPA dan pelatihan wirausaha ibu rumah tangga, diharapkan mampu meningkatkan life skills masyarakat dalam bidangnya. Beberapa kendala yang dihadapi yaitu dukungan pemerintah dan masyarakat dalam program $\mathrm{KKN}$ ini belum sepenuhnya terjalin serta tidak adanya dana yang cukup dalam realisasi program kerja di lapangan ${ }^{2}$.

2. PkM yang dilakukan oleh Duriani Sirajuddin dan Muhammad Iksan di Dusun Bassiang Kecamatan Ponrang Selatan Kabupaten Luwu ditemukan bahwa untuk mengurangi tingkat persentase masyarakat miskin, maka pemerintah butuh bekerjasama dengan perguruan tinggi melalui program KKN. Salah satunya dengan program pengembangan home industry di lokasi Dusun sasaran. Home industry mampu menjadi tulang punggung perekonomian bangsa yang mampu bertahan di saat krisis yang mampu melibatkan masyarakat miskin. Strategi pemberdayaan industri kecil meliputi strategi manajemen inovasi dan teknologi, pemberdayaan ibu-ibu rumah tangga, anak remaja yang putus sekolah, dan bapak-bapak yang sedang istirahat menggarap sawah. Dengan demikian, dengan adanya kegiatan tambahan bagi

${ }^{2}$ Saharuddin Saharuddin, "Pengabdian KKN-PPM Desa Wonorejo Kecamatan Mangkutana Kabupaten Luwu Timur," RESONA : Jurnal Ilmiah Pengabdian Masyarakat 1, no. 1 (2017): 2025, https://doi.org/10.35906/jipm01.v1i1.243. 
mereka akan membantu sebuah perubahan hidup yang lebih baik. Home industry Dempo' pisang aneka rasa, merupakan salah satu usaha yang akan dikembangkan di masyarakat Dusun Bassiang. Dengan adanya pembinaan, pelatihan, pameran, perlombaan dan studi banding ke tempat usaha lain, diharapkan menjadi usaha jangka panjang untuk meningkatkan taraf kehidupan masyarakat miskin di Dusun tersebut ${ }^{3}$.

3. PkM yang dilakukan oleh Ahmad Ulil Albab Al Umar menemukan bahwa pengabdian kepada masyarakat di tengah pandemi Covid-19 kali ini dapat dilakukan secara berkelompok langsung terjun ke lapangan maupun secara daring/online. Dengan adanya $\mathrm{KKN}$ ini, diharapkan agar mahasiswa tetap bisa melakukan pengabdian sehingga dapat mengembangkan kompetensi mereka. Oleh karena itu, hasil dari temuan ini adalah kegiatan KKN di masa pandemi masih tetap bisa dirasakan manfaatnya oleh masyarakat dan peran mahasiswa masih bisa dilakukan dengan rangkaian kegiatan inovatif serta tetap menjaga protokol kesehatan ${ }^{4}$.

Berdasarkan dari beberapa hasil PkM di atas, ditemukan bahwa kegiatan KKN selain berorientasi untuk meningkatkan kompetensi mahasiswa, juga diupayakan mampu meningkatkan potensi masyatakat. Ini merupakan sebuah langkah nyata dalam usaha melakukan perubahan di tengah masyarakat serta menjadi tangan kanan pemerintah dalam mewujudkan Dusun yang mandiri dan masyarakat yang berkualitas. Di antara bentuk program kerja mahasiswi STIBA angkatan IV yaitu, pengajaran murid Taman Kanak-kanak, pengajaran Al-Qur'an orang dewasa, pengajaran di sekolah Madrasah Tsanawiyah, Daurah Pra Ta'rif (Penataran dasar-dasar keislaman), dan Festival Anak Saleh.

\section{PEMBAHASAN}

\section{Pengajaran Taman Kanak-Kanak.}

Salah satu program kerja mahasisiwi adalah membantu para guru Taman Kanak-Kanak dalam mengajar. Dunia anak-anak bagi mahasiswi adalah sesuatu yang menyenangkan. Dengan demikian, untuk mendapat pengalaman, sekaligus meng-up grade kemampuan mengajarnya, maka mereka dilibatkan langsung dalam proses mengajar di Taman Kanak-kanak. Kegiatan ini dimulai dengan sosialisasi program dengan kepala sekolah dan pengaturan jadwal mengajar oleh

3 Muhammad Sirajuddin, Duriani. Iksan, "Berkemajuan: Jurnal Pengabdian Kepada Masyarakat Pengembangan Home Industri Dampo ' Pisang Aneka Rasa Melalui Kkn-Ppm Di Desa Bassiang Kecamatan Ponrang Selatan" 1 (2017): 22-25.

${ }^{4}$ Ahmad Ulil Albab AL Umar, "Peranan Kuliah Kerja Nyata Sebagai Wujud Pengabdian Kepada Masyarakat Di Tengah Pandemi Covid-19 (Studi Kasus IAIN Salatiga KKN 2021)," EAmal: Jurnal Pengabdian Kepada Masyarakat 01, no. 01 (2021): 39. 
mahasiswi KKN. Jadwal mengajar dimulai dari pukul 08.00 sampai pukul 09.20 pagi. Pada 15 menit awal dialokasikan sebagai persiapan belajar dengan duduk yang rapi serta melantunkan zikir pagi, kemudian pada pukul 08.20 - 09.20 adalah proses jam belajar berlangsung, dan pada pukul 09.20 adalah waktu untuk pulang.

Pengalaman menarik yang didapatkan oleh para mahasiswi dalam program ini adalah adanya peserta didik yang masih malu ketika para mahasiswi datang, dan terkadang kewalahan mengajari anak-anak yang aktif. Sementara itu, pada PkM yang dilakukan oleh Askar dan Jujuri menunjukkan bahwa semangat anakanak untuk belajar mengaji adalah faktor yang memudahkan proses pengumpulan anak-anak untuk belajar ${ }^{5}$. Adapun faktor-faktor yang mendukung program ini adalah antusias para guru memberikan dukungan kepada mahasiswi KKN untuk mengajarkan peserta didik doa-doa harian.

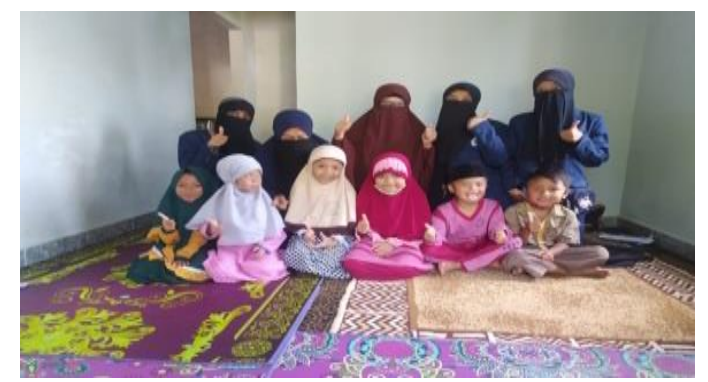

Gambar 1. Pengajaran Taman Kanak-Kanak

Kendala dalam program ini yaitu beberapa peserta didik kurang fokus dalam kegiatan pembelajaran dikarenakan semuanya ingin berbagi cerita satu sama lain. Untuk itu, solusi yang ditawarkan ialah dalam kegiatan belajar mengajar seyogianya dirangkaikan dengan games (ice breaking) agar peserta didik tidak bosan dan bisa kembali fokus untuk menerima pengajaran.

\section{Pengajaran Al-Qur'an Orang Dewasa (Tahsin)}

Kegiatan ini merupakan bentuk kerjasama dengan DPD Wahdah Islamiyah setempat dalam mendukung upaya pemerintah dalam peningkatan kualitas masyarakatnya. Sebelum program ini dimulai, maka mahsiswi meminta bantuan DPD dalam merancang program ini kemudian menentukan waktu yang tepat untuk pelaksanaan kegiatan. Sehubungan dengan itu, dengan program yang serupa, Sartini dan Akhmad melaksanakan kegiatan tahsin dimulai dengan pembukaan majelis, lalu pengajar menjelaskan materi tahsin kemudian masing-

5 Patahuddin, Askar, and Jujuri Perdamaian Dunia. "Menyiapkan SDM Unggul dan Religius melalui Ikhtiar Kegiatan Keagamaan di Desa Jonjo Kabupaten Gowa." WAHATUL MUJTAMA': Jurnal Pengabdian Masyarakat 1.2 (2020): 116-128. 
masing peseta mempraktikkannya ${ }^{6}$.

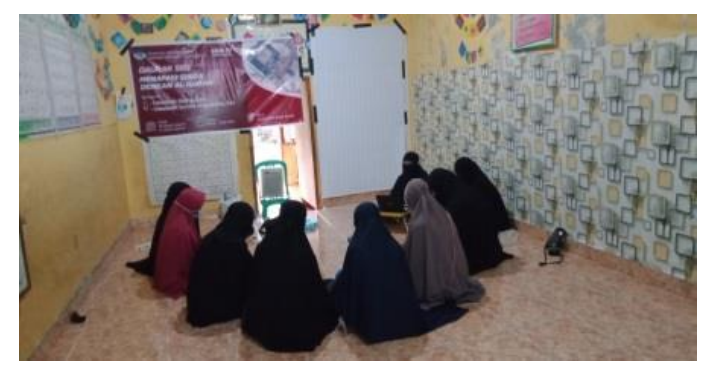

\section{Gambar 2. Pengajaran Al-Qur'an orang Dewasa (Tahsin)}

Pengalaman menarik yang diperoleh bersama ibu-ibu peserta ialah mereka memperlihatkan antusias yang tinggi dalam belajar sehingga mereka ingin sekali agar materi dalam buku tahsin bisa diselesaikan, padahal waktu KKN hanya sebulan. Adapun faktor yang mendukung, selain adanya kerjasama dan bantuan dari DPD WI setempat, terlihat juga antusias besar para peserta saat belajar. Kendala yang dihadapi dalam program ini karena terkadang bertabarkan dengan kegiatan lainnya di kampus yang mendadak. Untuk itu, diharapkan agar jauh-jauh hari jadwal kegiatan kampus dapat disampaikan.

\section{Pengajaran di Madrasah Tsanawiyah}

Selain mencari pengalaman mengajar di taman kanak-kanak, mahasiswi juga mencoba pengalaman lain mengajar di Madrasah Tsanawiyah di Dusun setempat. Program ini dimulai dengan sosialisasi program kerja dengan kepala sekolah, pengaturan jadwal mengajar, memahami bahan ajar yang akan diajarkan di madrasah, melatih siswa-siswi madrasah agar terbiasa bercakap dalam bahasa Arab, membiasakan siswa-siswi agar lebih sopan dan berakhlak kepada guru dan teman-temannya, serta mengarahkan siswa-siswi untuk membaca doa ketika ingin belajar dan selesai belajar. Adapun PkM yang dilakukan oleh Rachmat dan Khaerul pada pengajaran di Madrasah Tsanawiyah Ballasuka ialah membantu guru dalam memberikan mata pelajaran keagamaan berupa Al-Qur'an, hadis, dan fikih $^{7}$. Pengalaman menarik mahasiswi yaitu saat mengarahkan anak-anak dalam

${ }^{6}$ Lambajo, S., \& Yunta, A. H. D. (2020). Mewujudkan Masyarakat Qur'ani melalui Program KKN STIBA Makassar di Desa Kalabbirang Kabupaten Maros. WAHATUL MUJTAMA': Jurnal Pengabdian Masyarakat, 1(2), 157-173.

7 Tempo, Rachmat Bin Badani, and Khaerul Aqbar. "Ikhtiar Mahasiswa KKN STIBA Makassar dalam Pembentukan Akhlak Qur'ani Masyarakat Desa Balassuka Kabupaten Gowa." WAHATUL MUJTAMA': Jurnal Pengabdian Masyarakat 1.1 (2020): 90-115. 
kelas dan kemampuan memberikan nilai akhir. Siswa-siswi juga sangat senang ketika mendapatkan games di akhir sesi pembelajaran.

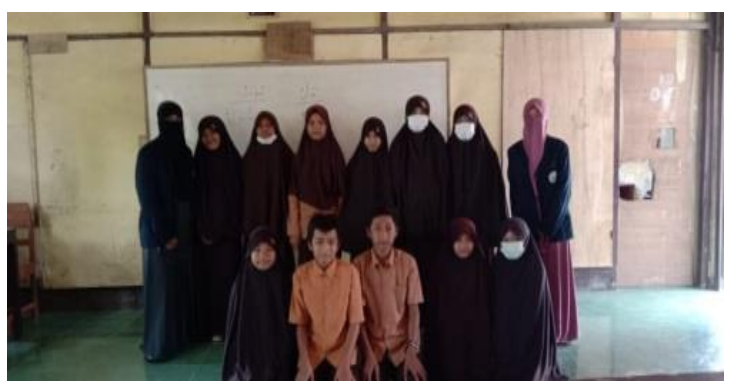

\section{Gambar 3. Pengajaran Madrasah Tsanawiyah Dusun Dasan Bagik}

Hal ini ditunjang oleh faktor yang mendukung kegiatan ini di antaranya ialah siswa-siswi sangat ramah dan guru sekolah madrasah selalu memberi pengarahan dengan baik. Para siswa-siswi juga memperlakukan guru dan mahasiswi KKN sebagai kakak yang dihormati di luar sekolah. Adapun kendala yang ditemui dalam program ini adalah seringnya didapati dan diperhadapkan pada jadwal mengajar yang bertabrakan sehingga menyebabkan harus terlambat masuk kelas. Maka kendala ini dapat diatasi dengan mangatur jadwal dengan baik.

\section{Daurah Pra Ta'rif(Penataran Dasar Keislaman)}

Daurah Pra Ta'rif atau penataran seputar dasar-dasar keislaman merupakan kegiatan pengenalan ilmu dasar-dasar keislaman kepada masyarakat muslim (dalam hal ini muslimah) yang masih awam. Program ini dilaksanakan dengan terlebih dahulu dengan merancang konsep kegiatan. Kemudian menyebarkan pamflet daurah di media sosial, mempersiapkan semua sarana dan prasarana yang dibutuhkan, gladi bersih hingga kegiatan dapat dilakukan dengan baik. Hal ini serupa dengan kegiatan taklim muslimah, di mana bertujuan untuk tujuannya ialah memberikan materi dan pencerahan, menambah wawasan tentang keislaman ${ }^{8}$.

${ }^{8}$ Putri, Sri Ujiana, and Aswar Aswar. "Implementasi Pendidikan Masyarakat Berbasis Masjid untuk Muslimah di Desa Mattoanging Kabupaten Maros." WAHATUL MUJTAMA': Jurnal Pengabdian Masyarakat 1.2 (2020): 129-141. 
Website: https://journal.stiba.ac.id ISSN: 2723-6013 (Online)

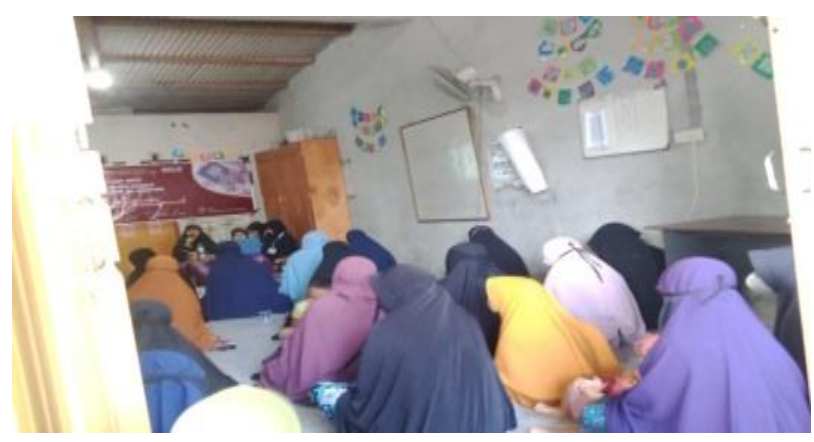

Gambar 4. Daurah Pra Ta'rif

Pengalaman menarik yang didapatkan oleh para mahasiswi KKN dalam kegiatan ini adalah masyarakat tidak canggung lagi untuk berkomunikasi dengan mahasiswi KKN, meskipun mereka semua bercadar. Hal lain juga dikarenakan mahasiswi bisa berbahasa Sasak dan mereka senang telah dikenal oleh masyarakat setempat. Adapun di antara faktor yang mendukung kegiatan ini adalah masyarakat menerima setiap program yang diadakan dengan baik, bahkan di antara mereka ada yang menyampaikan usulan-usulan dan harapan terkait program yang dilaksankan. Selain itu, warga juga memberikan dukungan, baik moral dan materil.

\section{Festival Anak Saleh}

Kegiatan ini merupakan rangkaian program kerja yang bertujuan untuk melatih anak-anak dalam mengasah kemampuannya dan berani tampil di depan umum. Sehubungan dengannya, melalui PkM Aswar, dkk, menunjukkan bahwa kegiatan Festival Anak Saleh dapat berpengaruh pada stumulasi perubahan dari aspek perilaku ibadah, adab, dan akhlak pada diri anak ${ }^{9}$. Adapun kegiatan ini dimulai dengan merancang konsep kegiatan, memberikan pelatihan kepada anakanak sebelum tampil hingga kegiatan yang dapat dilaksankan dengan baik.

Pengalaman menarik yang didapatkan mahasiswi KKN dalam kegiatan ini adalah saat anak-anak meminta agar mereka diberikan pelajaran bahasa Arab, sebagai pembelajaran yang belum pernah mereka dapatkan sebelumnya. Adapun faktor yang mendukung kegiatan ini adalah antusias yang besar dari para orang tua agar anak-anak mereka dapat ikut festival. Namun, kegiatan ini terkendala dikarenakan ketersediaan dana yang sangat minim. Untuk itu, solusi ke depannya ialah agar para mahasiswi KKN dapat melakukan pengumpulan atau penggalangan dana yang dikhususkan untuk kegiatan semacam ini.

9 Aswar, Aswar, and Rosmita Rosmita. "Festival Anak Saleh di Desa Leang-leang Kabupaten Maros." WAHATUL MUJTAMA': Jurnal Pengabdian Masyarakat 1.1 (2020): 54-66. 


\section{KESIMPULAN}

Kuliah Kerja Nyata (KKN) STIBA Makassar angkatan IV bertujuan untuk mengamalkan Tri Dharm Perguruan Tinggi sebagai wujud pengabdian kepada masyarakat. Di antara program kerja yang dilaksanakan adalah pengajaran Taman Kanak-kanak, pengajaran Al-Qur'an orang dewasa (tahsin), pengajaran di Madrasah Tsanawiyah, daurah pra ta'rif dan FAS (Festival Anak Saleh). Dengan program ini, masyarakat Dusun Dasan Bagik sangat antusias dan berharap agar kegiatan semacam ini terus berlanjut. Mahasiswi KKN berharap agar kegiatan peningkatan keilmuan dan kompetensi masyarakat dapat terus dicanangkan demi mewujudkan Dusun yang mandiri dan berkualitas.

\section{DAFTAR PUSTAKA}

Aswar, Aswar, and Rosmita Rosmita. "Festival Anak Saleh di Desa Leang-leang Kabupaten Maros." WAHATUL MUJTAMA': Jurnal Pengabdian Masyarakat 1.1 (2020): 54-66.

Patahuddin, Askar, and Jujuri Perdamaian Dunia. "Menyiapkan SDM Unggul dan Religius melalui Ikhtiar Kegiatan Keagamaan di Desa Jonjo Kabupaten Gowa." WAHATUL MUJTAMA': Jurnal Pengabdian Masyarakat 1.2 (2020): 116-128.

Putri, Sri Ujiana, and Aswar Aswar. "Implementasi Pendidikan Masyarakat Berbasis Masjid untuk Muslimah di Desa Mattoanging Kabupaten Maros." WAHATUL MUJTAMA': Jurnal Pengabdian Masyarakat 1.2 (2020): 129141.

Saharuddin, Saharuddin. "Pengabdian KKN-PPM Dusun Wonorejo Kecamatan Mangkutana Kabupaten Luwu Timur." RESONA: Jurnal Ilmiah Pengabdian Masyarakat 1, no. 1 (2017): 20-25. https://doi.org/10.35906/jipm01.v1i1.243.

Sirajuddin, Duriani. Iksan, Muhammad. "Berkemajuan: Jurnal Pengabdian Kepada Masyarakat Pengembangan Home Industri Dampo ’ Pisang Aneka Rasa Melalui Kkn-Ppm Di Dusun Bassiang Kecamatan Ponrang Selatan" 1 (2017): 22-25.

Tempo, Rachmat Bin Badani, and Khaerul Aqbar. "Ikhtiar Mahasiswa KKN STIBA Makassar dalam Pembentukan Akhlak Qur'ani Masyarakat Desa Balassuka Kabupaten Gowa." WAHATUL MUJTAMA': Jurnal Pengabdian Masyarakat 1.1 (2020): 90-115.

Umar, Ahmad Ulil Albab AL. "Peranan Kuliah Kerja Nyata Sebagai Wujud Pengabdian Kepada Masyarakat Di Tengah Pandemi Covid-19 (Studi Kasus IAIN Salatiga KKN 2021)." E-Amal: Jurnal Pengabdian Kepada Masyarakat 01, no. 01 (2021): 39. 